\title{
Wet-Chemically Prepared NiO Layers as Hole Transport Layer in the Inverted Organic Solar Cell
}

\author{
Dong Chan Lim, ${ }^{\dagger}$ Young Tae Kim, ${ }^{\dagger}$ Won Hyun Shim, ${ }^{\dagger, \dagger}$ A-Young Jang, Jae-Hong Lim, ${ }^{\dagger}$ \\ Yang Do Kim, ${ }^{\ddagger}$ Yongsoo Jeong, ${ }^{\ddagger}$ Young Dok Kim,,${ }^{\S, *}$ and Kyu Hwan Lee ${ }^{\dagger, *}$ \\ ${ }^{\dagger}$ Material Processing Division, Korea Institute of the Materials Science, Changwon, Gyeongnam 642-831, Korea \\ ${ }^{*}$ E-mail: lgh1636@kims.re.kr \\ School of Materials Science and Engineering, Pusan National University, Geumjeong-gu, Busan 609-735, Korea \\ ${ }^{\S}$ Department of Chemistry, Sungkyunkwan University, Suwon 440-746, Korea. *E-mail: ydkim91@skku.edu \\ Received November 30, 2010, Accepted January 8, 2011
}

Key Words : NiO, Surface roughness, Solvent, Annealing, Inverted organic solar cells

One of the clean alternative energy sources attracting particular attention is solar cells, which can convert the solar light directly to electricity. ${ }^{1-7}$ Diverse solar cells have been developed so far, and particularly, organic solar cells (OSCs) have been attracting much attention due to their low cost as well as potential applications in flexible energy conversion devices. OSCs with power conversion efficiency (PCE) of $5-6 \%$ have been recently developed by several research groups. ${ }^{8-10}$ One of well-known disadvantages of OSCs is its very low stability under atmospheric pressure conditions: the performance of the OSCs can stand only for several days. In order to improve the stability of OSCs, inverted structures of OSCs have been developed. ${ }^{11-18}$ In contrast to the conventional structure, in which holes are injected into the transparent conducting electrode (TCE), electrons are directed towards TCE. Inorganic semiconducting materials such as $\mathrm{TiO}_{2}$ or $\mathrm{ZnO}$ deposited on the Indium Tin Oxide (ITO) electrode can be used as buffer layer for accepting electrons, which can also significantly increase the stability of inverted OSCs (IOSCs).

In most of the bulk heterojunction (BHJ) OSCs, poly(4styrene sulfonate)-doped poly(3,4-ethylenedioxythiophene (PEDOT:PSS) is widely used as hole transport layers (HTL). PEDOT:PSS can be replaced by $p$-type semiconductors. It has been demonstrated that several metal oxides can show high ability for hole injection in organic light-emitting diodes (OLEDs). ${ }^{19,20}$ Recently, $p$-type metal oxide thin film such as $\mathrm{V}_{2} \mathrm{O}_{5}, \mathrm{MO}_{3}$, and $\mathrm{NiO}$ etc. were used as HTL in $\mathrm{OSCs}^{4,21-27}$ It should be noted that previous studies mostly used vacuum deposition technique for the fabrication of the metal oxide thin films. In contrast to the previous studies, we aim in obtaining $\mathrm{NiO}$-based IOSCs, with all fabrication step except for the top electrode preparation proceeded under atmospheric conditions and in solutions. Experimental parameters for depositing $\mathrm{NiO}$ films using solution-based method have been optimized for obtaining a high efficiency of IOSCs without PEDOT:PSS. We demonstrate that a PCE of $3 \%$ can be reached by using solution-based preparation of $\mathrm{NiO}$ films, and the photovoltaic performance of this IOSCs is comparable to that of the device consisting of

\section{PEDOT:PSS}

\section{Experimental Details}

IOSCs consisted of a stack of $\mathrm{Ag} / \mathrm{NiO} / \mathrm{P} 3 \mathrm{HT}: \mathrm{PCBM} /$ $\mathrm{ZnO}$ buffer layer/patterned ITO substrate $\left(10 \Omega / \mathrm{cm}^{2}\right)$. For the preparation of $\mathrm{ZnO}$ sol-gel solutions zinc acetate $\left[\mathrm{Zn}\left(\mathrm{CH}_{3} \mathrm{COO}\right)_{2} \cdot \mathrm{H}_{2} \mathrm{O}\right]$ was dissolved in 2-methoxyethanol solution containing ethanolamine as a stabilizer. Concentration of zinc acetate was $0.75 \mathrm{M}$. This solution was stirred at $60{ }^{\circ} \mathrm{C}$ for $30 \mathrm{~min}$ to yield a clear and homogeneous solution, which served as the coating solution. After spin coating of $\mathrm{ZnO}$ on ITO-substrate, the films were annealed at $220{ }^{\circ} \mathrm{C}$ for 10 minutes.

For the preparation of active layer, a mixture of RR-P3HT $(30 \mathrm{mg} / \mathrm{mL})$ and PCBM $(21 \mathrm{mg} / \mathrm{mL})$ was dissolved in 1,2dichlorobenzene under vigorous stirring overnight. Then, this solution was spin-coated on $\mathrm{ZnO}$ films deposited on ITO under atmospheric pressure at room temperature. $\mathrm{NiO}$ powder with a mean diameter of $50 \mathrm{~nm}$ (Reagent-grade chemical) was dissolved in solvents. Three different solvents

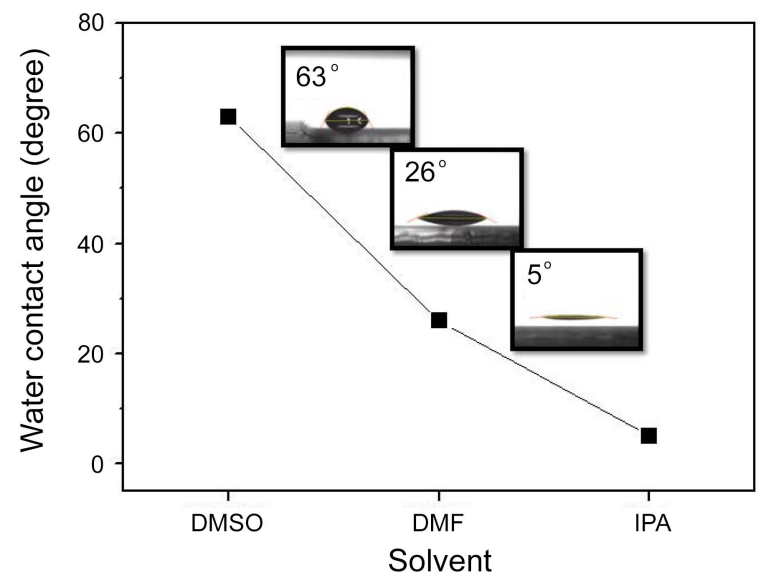

Figure 1. Contact angles of various solvents (DMF, DMSO, and IPA) on NiO films over active layers (P3HT/PCBM) are displayed. For the preparation of each $\mathrm{NiO}$ film, spin-coating with the respective solvent was used with a $\mathrm{NiO}$ concentration of $5 \times 10^{-4} \mathrm{M}$. 
(isopropylalcohol IPA, dimethylsulfoixde DMSO and dimethylformamide DMF) were used for dissolving $\mathrm{NiO}$ in the present work as shown in Figure 1. NiO was deposited on top of active layer using spin coating with a rate of 1000 $\mathrm{rpm}$ for $1 \mathrm{~min}$. The top electrode $(\mathrm{Ag})$ was deposited by thermal evaporation method with a thickness of $100 \mathrm{~nm}$ under $5 \times 10^{-6}$ torr condition. The active-area of the device with metal mask was $0.38 \mathrm{~cm}^{2}$. The completely fabricated devices were baked at $150^{\circ} \mathrm{C}$ for 5 min under air.

The structures of $\mathrm{ZnO}$ and $\mathrm{NiO}$ films were analyzed by field emission scanning electron microscopy (FE-SEM; JEOL 6000 ) and atomic force microscopy(AFM, Vecco; MMAFM2 ), and their optical properties were measured using UV/Vis transmittance spectrometer (Verian Cary 5000), respectively. The performances of the solar cells were tested using a solar simulator illuminated with a photointensity of AM 1.5, $100 \mathrm{~mW} / \mathrm{cm}^{2}$. Contact angle was measured for studying wettability of solvent and $\mathrm{NiO}$.

\section{Results and Discussion}

Figures 1 and 2 demonstrate how we have optimized experimental parameters for deposition of $\mathrm{NiO}$ films on top of active layers using spin-coating. First, various solvents were used for the preparation of $\mathrm{NiO}$ solutions, which were used for spin-coating $\mathrm{NiO}$ films, and attempts were made for selecting the best solvent. Figure 1 shows the contact angles of various solvents on $\mathrm{NiO}$ films over active layers. $\mathrm{NiO}$ films were deposited using spin-coating and for each sample, the respective solvent was used for film deposition. For the $\mathrm{NiO}$ film deposition using spin-coating, a NiOsolution of $5 \times 10^{-4} \mathrm{M}$ in concentration was used for all three solvents. Among three solvents compared here (DMF, DMSO and IPA), IPA showed the lowest contact angle ( $\left.5^{\circ}\right)$ on $\mathrm{NiO}$, i.e. it is likely that $\mathrm{NiO}$ is best dispersed in IPA among three different solvent studied here. Therefore, it is expected that use of IPA should result in the most highly dispersed $\mathrm{NiO}$ film structure on active layers. Considering that well-dispersed $\mathrm{NiO}$ film on active layers is needed for a better contact between HTL and top electrodes, we suggest that IPA should be used as solvent of $\mathrm{NiO}$. In fact, $\mathrm{NiO}$ films prepared using IPA showed a better photovoltaic performance of the IOSC than those with other solvents (DMSO and DMF, data not shown).

Figure 2 shows that annealing temperature can have influence on the surface morphology of $\mathrm{NiO}$ films. When active layer was annealed at $80{ }^{\circ} \mathrm{C}$, and $\mathrm{NiO}$ was subsequently spin-coated, a relatively smooth surface structure was formed (Fig. 2(b)). In this case, the concentration of $\mathrm{NiO}$-solution using IPA as solvent was $1 \times 10^{-3} \mathrm{M}$. Upon a subsequent annealing of the $\mathrm{NiO} /$ active layer structure at $150{ }^{\circ} \mathrm{C}$, the smooth surface structure was still maintained (Fig. 2(c)). When the active layer was annealed at $150{ }^{\circ} \mathrm{C}$ prior to $\mathrm{NiO}$ deposition, in contrast, post-annealing of $\mathrm{NiO}$ film at $150{ }^{\circ} \mathrm{C}$ resulted in a higher surface roughness (Fig. 2(e)). In order to prepare highly dispersed $\mathrm{NiO}$ films, the active layer should be annealed at $80{ }^{\circ} \mathrm{C}$ prior to $\mathrm{NiO}$

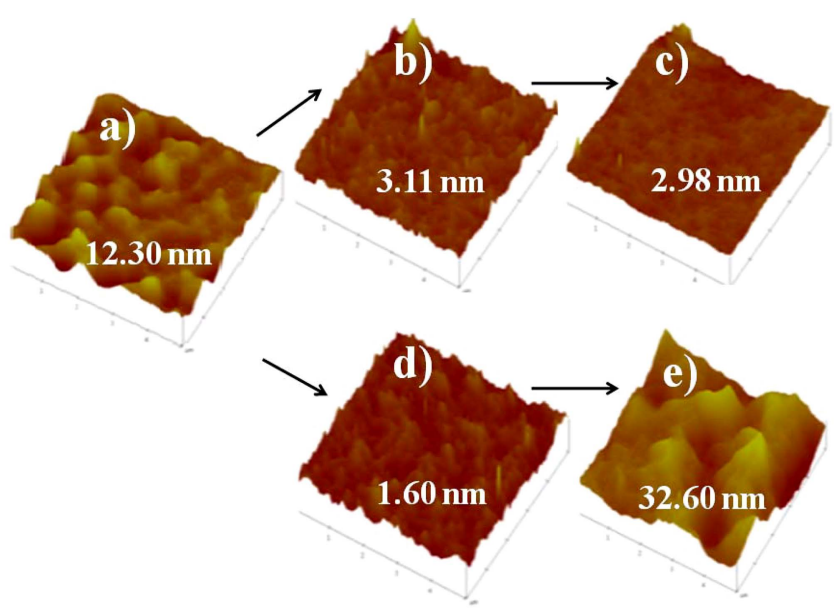

Figure 2. AFM images of the surfaces of bare active layers and those of $\mathrm{NiO}$ on top of the active layers treated under different conditions are compared. For $\mathrm{NiO}$ deposition using spin-coating, IPA was used as solvent with a $\mathrm{NiO}$ concentration of $1 \times 10^{-3} \mathrm{M}$. (a) The active layers were annealed at $80^{\circ} \mathrm{C}$ for $10 \mathrm{~min}$. (b) $\mathrm{NiO}$ was deposited on the surface of (a). (c) Sample (b) was annealed at $150{ }^{\circ} \mathrm{C}$ for $10 \mathrm{~min}$. (d) Film (a) was annealed at $150{ }^{\circ} \mathrm{C}$ for $10 \mathrm{~min}$. (e) Film (d) was annealed at $80{ }^{\circ} \mathrm{C}$ for $10 \mathrm{~min}$, and subsequently, NiO film was deposited.

(a)

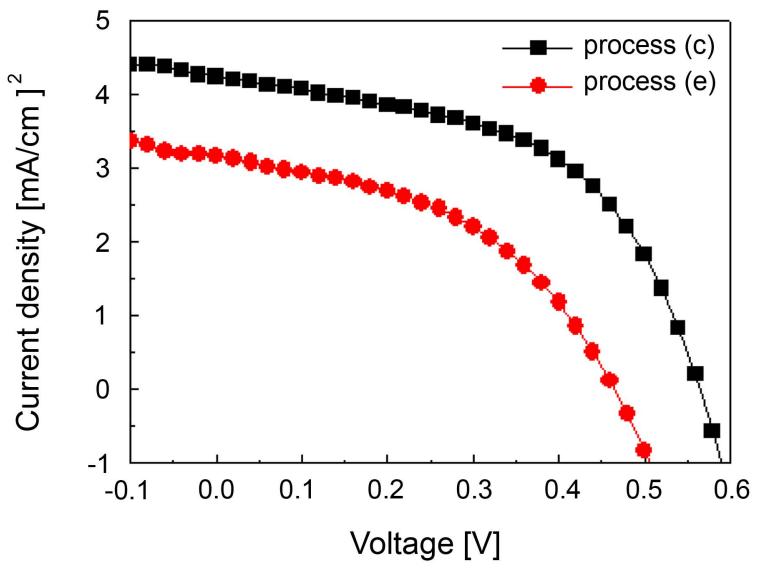

(b)

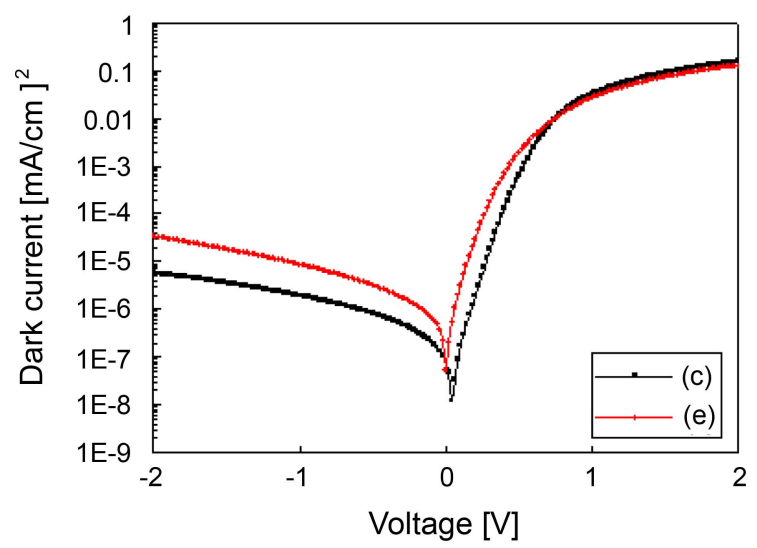

Figure 3. (a) The J-V characteristics of devices based on two different NiO films shown in Figure 2(c) and (e) as HTL. (b) Dark currents as a function of voltage are compared for two different devices consisting of $\mathrm{NiO}$ layers in Figure 2(c) and (e), respectively. 
Table 1. Photovoltaic performances (PCE, FF, $\mathrm{V}_{\mathrm{oc}}, \mathrm{J}_{\mathrm{sc}}$ and $\mathrm{R}_{\mathrm{sc}}$ ) for two different devices in Figure 3 are compared.

\begin{tabular}{cccccc}
\hline & PCE (\%) & FF (\%) & $\mathrm{V}_{\text {oc }}(\mathrm{V})$ & $\mathrm{J}_{\mathrm{sc}}\left(\mathrm{mA} / \mathrm{cm}^{2}\right)$ & $\left.\mathrm{R}_{\mathrm{s}}(\mathrm{W} \mathrm{cm})^{2}\right)$ \\
\hline (c) & 1.24 & 0.52 & 0.56 & 4.24 & 7.56 \\
(e) & 0.66 & 0.45 & 0.46 & 3.16 & 8.94 \\
\hline
\end{tabular}

deposition.

We constructed IOSCs based on two different $\mathrm{NiO}$ films shown in Figure 2(c) and (e) (Fig. 3, Table 1). These two $\mathrm{NiO}$ films show much different surface structures with root mean square (RMS) roughness values of 2.98 and $32.60 \mathrm{~nm}$, respectively, which were determined by AFM. For the devices shown in Figure 3, the thickness of active layers (P3HT/PCBM) was $370 \mathrm{~nm}$. When the smoother NiO surface was used for constructing the IOSC, PCE of 1.24\% could be reached, whereas the rougher $\mathrm{NiO}$ film resulted in a PCE value of only $0.66 \%$. This result implies that a lower roughness of $\mathrm{NiO}$ is essential for obtaining a better photovoltaic performance. Fill-factor $(\mathrm{FF})$, open-circuit voltage $\left(\mathrm{V}_{\mathrm{oc}}\right)$, short-circuit current $\left(\mathrm{J}_{\mathrm{sc}}\right)$ of the device with a lower roughness of $\mathrm{NiO}$ were all higher than the respective values of the device consisting of a $\mathrm{NiO}$ film with a higher surface roughness. In Figure 3(b), and Table 1, it is also shown that the dark current and series resistance of the IOSC with a smoother $\mathrm{NiO}$ are lower than those of the device with a rougher $\mathrm{NiO}$ film surface, leading to increase in $\mathrm{FF}$ and $\mathrm{Voc}$ values.

We have made efforts for improving the device efficiency using NiO as HTL by varying thickness of active layers. When the thickness of active layers was $500 \mathrm{~nm}$, a PCE of $3.01 \%$ could be obtained. Increase in the active layer thickness can enhance the absorption of photon, resulting in increased $\mathrm{J}_{\mathrm{sc}}$ value. For this device, $\mathrm{FF}, \mathrm{V}_{\mathrm{oc}}$, and $\mathrm{J}_{\mathrm{sc}}$ were $51 \%, 0.58 \mathrm{~V}$, and $10.07 \mathrm{~mA} / \mathrm{cm}^{2}$, respectively. It is worth mentioning that further increase in the active layer thickness can decrease the PCE, since for example, the diffusion length of the exciton is limited. Since photon absorption of active layers is dependent of electrode materials, the thickness of the active layer should be optimized for each device.

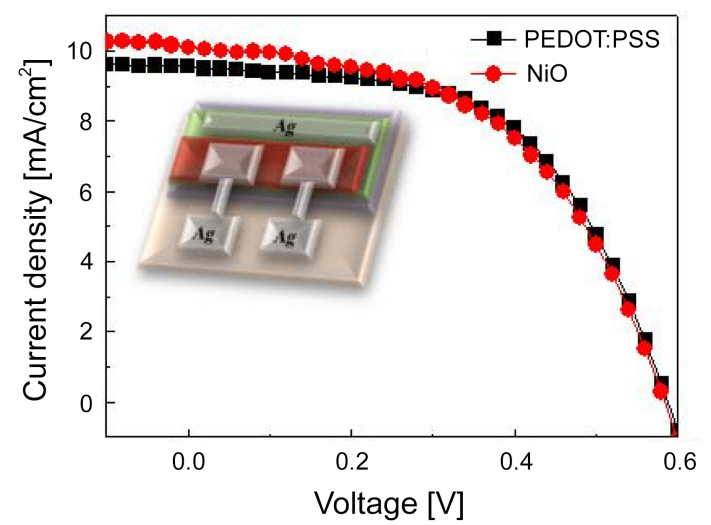

Figure 4. The J-V characteristics of inverted organic solar cells using PEDOT:PSS and $\mathrm{NiO}$ as hole transporting layers, respectively, are compared.
Table 2. Photovoltaic performances (PCE, FF, $\mathrm{V}_{\mathrm{oc}}, \mathrm{J}_{\mathrm{sc}}$ and $\mathrm{R}_{\mathrm{sc}}$ ) for two different IOSCs with PEDOT:PSS and NiO as HTL in Figure 4 are compared

\begin{tabular}{ccccc}
\hline & PCE $(\%)$ & FF $(\%)$ & $\mathrm{V}_{\mathrm{oc}}(\mathrm{V})$ & $\mathrm{J}_{\mathrm{sc}}\left(\mathrm{mA} / \mathrm{cm}^{2}\right)$ \\
\hline PEDOT:PSS & 3.11 & 55 & 0.58 & 9.54 \\
$\mathrm{NiO}$ & 3.01 & 51 & 0.58 & 10.07 \\
\hline
\end{tabular}

The photovoltaic performance of the NiO-based device was shown to be comparable to the IOSC using PEDOT:PSS, as shown in Figure 4 and Table 2. The PCE of the NiO-based device was lower than that of the device using PEDOT:PSS only by $0.1 \%$, and regarding the $\mathrm{J}_{\mathrm{sc}}$ value, the NiO-based solar cell was superior to the conventional solar cell consisting of PEDOT:PSS.

\section{Summary}

We have demonstrated that solution-based fabrication of $\mathrm{NiO}$ films as HTL can be used for the construction of IOSCs. Type of solvent of NiO-solution, and annealing procedure of the active layers were optimized for obtaining a PCE of 3\% of IOSC. The photovoltaic performance of NiO-based device is comparable to that of the same type of solar cell using PEDT:PSS instead of NiO. These solution-based processes can be a promising method for a mass production OSCs under ambient condition.

Acknowledgments. This work was supported by the Korea Foundation for International Cooperation of Science and Technology (KICOS) through a grant provided and by the Korea Institute of Materials Science (KIMS).

\section{References}

1. Tang, C. W. Appl. Phys. Lett. 1986, 48, 183.

2. Xue, J.; Uchida, S.; Rand, B. P.; Forrest, S. R. Appl. Phys. Lett. 2004, 84, 3013.

3. Reyes-Reyes, M.; Kim, K.; Carroll, D. L. Appl. Phys. Lett. 2005, 87, 083506

4. Chu, C.-W.; Shao, Y.; Shrotriya, V.; Yang, Y. Appl. Phys. Lett. 2005, 86, 243506.

5. Yu, G.; Gao, J.; Hummelen, J. C.; Wudl, F.; Heeger, A. J. Science 1995, 270, 1789.

6. Spanggaard, H.; Krebs, F. C. Sol. Ener. Mater. Sol. Cells 2004, 83, 125.

7. Thompson, B.; Fréchet, J. Angew. Chem. Int. Ed. 2008, 47, 58.

8. Kim, J.; Kim, S.; Lee, H. H.; Lee, K.; Ma, W.; Gong, X.; Heeger, A. Adv. Mater. 2006, 18, 572.

9. Kim, J. Y.; Lee, K.; Coates, N. E.; Moses, D.; Nguyen, T.-Q.; Dante, M.; Heeger, A. J. Science 2007, 317, 222.

10. Irwin, M. D.; Buchholz, D. B.; Hains, A. W.; Chang, R. P. H.; Marks, T. J. Proc. Nat. Ac. Sci. 2008, 105, 2783.

11. Olson, D. C.; Shaheen, S. E.; Collins, R. T.; Ginley, D. S. J. Phys. Chem. C 2007, 111, 16670.

12. Olson, D. C.; Piris, J.; Collins, R. T.; Shaheen, S. E.; Ginley, D. S. Thin Solid Films 2006, 496, 26.

13. Ravirajan, P.; Peircj, A. M.; Nazeeruddin, M. K.; Graetzel, M.; Bradley, D. D. C.; Durrant, J. R.; Nelson, J. J. Phys. Chem. B 2006, 110, 7635.

14. Savenije, T. J.; Warman, J. M.; Goossens, A. Chem. Phys. Lett. 
1998, 287, 148.

15. Arango, A. C.; Johnson, L. R.; Bliznyuk, V. N.; Schlesinger, Z.; Carter, S. A.; Hörhold, H. H. Adv. Mater. 2000, 12, 1689.

16. Breeze, A. J.; Schlesinger, Z.; Carter, S. A.; Brock, P. J. Phys. Rev. $B$ 2001, 64, 125205.

17. Fan, Q.; McQuillin, B.; Bradley, D. D. C.; Whitelegg, S.; Seddon, A. B. Chem. Phys. Lett. 2001, 347, 325.

18. Liu, J.; Tanaka, T.; Sivula, K.; Alivisatos, A. P.; Frechet, J. M. J. J. Am. Chem. Soc. 2004, 126, 6550.

19. Shizuo, T.; Noda, K.; Taga, Y. J. Phys. D: Appl. Phys. 1996, 29, 2750.

20. You, H.; Dai, Y.; Zhang, Z.; Ma, D. J. Appl. Phys. 2007, 101, 026105.

21. Li, G.; Chu, C. W.; Shrotriya, V.; Huang, J.; Yang, Y. Appl. Phys.
Lett. 2006, 88, 253503.

22. Tao, C.; Ruan, S.; Zhang, X.; Xie, G.; Shen, L.; Kong, X.; Dong, W.; Liu, C.; Chen, W. Appl. Phys. Lett. 2008, 93, 193307.

23. Kyaw, A. K. K.; Sun, X. W.; Jiang, C. Y.; Lo, G. Q.; Zhao, D. W.; Kwong, D. L. Appl. Phys. Lett. 2008, 93, 221107.

24. Zhao, D. W.; Liu, P.; Sun, X. W.; Tan, S. T.; Ke, L.; Kyaw, A. K. K. Appl. Phys. Lett. 2009, 95, 153304.

25. Liao, H.-H.; Chen, L.-M.; Xu, Z.; Li, G.; Yang, Y. Appl. Phys. Lett. 2008, 92, 173303.

26. Takanezawa, K.; Tajima, K.; Hashimoto, K. Appl. Phys. Lett. 2008, 93, 063308 .

27. Bang-Ying, Y.; Tasi, A.; Shu-Ping, T.; Ken-Tsung, W.; Yang, Y.; Chih-Wei, C.; Jing-Jong, S. Nanotechnol. 2008, 19, 255202. 